Article

\title{
The Influence of Ball Burnishing on Friction in Lubricated Sliding
}

\author{
Slawomir Swirad *(1) and Pawel Pawlus \\ Faculty of Mechanical Engineering and Aeronautics, Rzeszow University of Technology, Powstancow Warszawy \\ 8 Street, 35-959 Rzeszow, Poland; ppawlus@prz.edu.pl \\ * Correspondence: ssktmiop@prz.edu.pl; Tel.: +48-17-865-1904
}

Received: 11 October 2020; Accepted: 5 November 2020; Published: 7 November 2020

check for updates

\begin{abstract}
Ball burnishing treatment, using the Ecoroll system, of steel samples was conducted. In the experiment, the burnishing pressure was changed. After the treatments, measurements of the surface topographies of disc samples were conducted using a white light interferometer Talysurf CCI Lite. Tribological tests were carried out in a ball-on-disc configuration. After these tests, measurements of surface topographies of disc samples were repeated. Worn surfaces were also analyzed with a scanning electron microscope. It was found that as the result of burnishing, surface topography height of tested samples decreased. Ball burnishing led to a reduction in the frictional resistance. The highest friction reduction of more than $40 \%$ was achieved with a burnishing pressure of $20 \mathrm{MPa}$.
\end{abstract}

Keywords: ball burnishing; coefficient of friction; surface topography

\section{Introduction}

Ball burnishing is a loss-free finishing process used for improving surface quality. In addition, compressive residual stresses are introduced with an increase in hardness, leading to an improvement in the subsurface integrity $[1,2]$. In this process, a hard ball is pressed against the sample and slides over its surface [3]. Surface and subsurface integrity can be improved by plastic deformation. Ball burnishing can be combined with other treatments, such as turning [1], grinding [4] and superfinishing [5]. Researchers typically obtained a reduction in surface height as a result of burnishing [6-12]. An increase in microhardness was reported in [11-14], while the addition of compressive residual stresses was reported in $[1,12,14]$. Various burnishing parameters are related to a reduction in surface roughness due to burnishing. For instance, Korzynski and Zarski [7] changed the burnishing force and the tool diameter, Skoczylas and Swirad [15] changed the pressure and the burnishing rate and Dzionk et al. [16] changed feed and burnishing speed.

The improvement of functional properties of samples after ball burnishing is typically attributed to subsurface properties such as microhardness and residual stresses [17-19].

However, surface topography of burnished samples can also affect frictional resistance, especially in lubricated conditions. It is difficult to find technical literature papers presenting the effects of ball burnishing on the frictional behaviors of sliding pairs-only results related to surfaces after other treatments have been presented. Dzierwa et al. [20] found that smoother surfaces produced less friction in pin-on-disc lubricated contact. The friction force was proportional to roughness height in studies conducted by Sedlacek et al. [21,22]. The friction force between nanometer thick lubricant films was higher when the composite rms. (root mean square) height of two solid surfaces was also higher [23]. However, the opposed effects of surface roughness height on lubricated friction were also obtained. In the work [24], the friction of rough steel surfaces was higher compared to that of smooth surfaces under boundary lubrication. 
The height of surface texture is typically assessed by averaged parameters such as the standard deviation of height (Sq) [25]. However, for two-process textures, the standard deviation of the plateau height affected the friction coefficient. Two-process surfaces have tracks of two-machining processes. They were prepared to resemble textures created during running-in. They combine good sliding properties of smooth surfaces with the ability to maintain the oil of porous textures. Jeng [26] found that in mixed lubrication, two-process surfaces yielded less friction that a one-process texture, of similar standard deviation of height. Cylinder texture after finish honing and plateau honing was one of the earlier examples of two-process surfaces [27-29]. Plateau honing is also one of the first examples of surface texturing, which depends on the creation of connected or isolated dimples on sliding surfaces. The dimple can be a micro-hydrodynamic bearing in full or mixed lubrication, a micro-reservoir for lubricant in starved lubrication or a micro-trap for wear debris [30-32].

As aforementioned, it is difficult to find in technical literature publications about the impact of the ball burnishing process on the frictional resistance in lubricated contact. The present authors of this study try to fill this gap.

\section{Experimental Details}

Ball burnishing treatment, using the Ecoroll system, of samples from 42CrMo4 (chromiummolybdenum steel for quenching and tempering) steel of $34 \pm 2$ HRC hardness, was carried out using the CNC Mill Center VF-1 (Haas Automation Inc., Oxnard, CA, USA). In the experiment, the burnishing pressure, delivered by a hydraulic pump, was the input parameter. There were the following values of the burnishing pressure (P): 10, 20, 30 and $40 \mathrm{MPa}$. Burnishing speed was $0.5 \mathrm{~m} / \mathrm{min}$, while burnishing width was $0.01 \mathrm{~mm}$. The samples were milled before the burnishing process. Table 1 presents the parameters of milling.

Table 1. Milling parameters.

\begin{tabular}{cccc}
\hline $\begin{array}{c}\text { Rotational Speed } \\
\text { n, rev/min }\end{array}$ & Feed Per Tooth, vz, mm/Tooth & $\begin{array}{c}\text { Depth of Cut Speed } \\
\text { ap, } \mathbf{~ m m}\end{array}$ & $\begin{array}{c}\text { Feed Speed } \\
\text { vf, mm/min }\end{array}$ \\
\hline 950 & 0.1 & 0.2 & 400 \\
\hline
\end{tabular}

After the treatments, the surface topographies of milled and burnished samples were measured using an optical profilometer (Talysurf CCI Lite (Taylor Hobson Ltd., Leicester, UK)) of $0.01 \mathrm{~nm}$ vertical resolution. The objective $5 \times$ was used, so the measuring areas (containing $1024 \times 1024$ points) were $3.29 \mathrm{~mm} \times 3.29 \mathrm{~mm}$. Parameters of disc surface texture were computed using TalyMap 6 software (Digital Surf, Besancon, France). The form was eliminated by surface leveling. Surface topographies of analyzed samples were also measured after tribological tests and analyzed using SEM. SEM images were acquired with the Phenom ProX desktop scanning electron microscope equipped with a thermionic $\mathrm{CeB}_{6}$ (cerium hexaboride) source and a high sensitivity multi-mode backscatter detector (BSD). The SEM measurement was performed at a voltage of $10 \mathrm{kV}$, the imaging magnifications were commonly fixed 620 times. The sizes of the images of the SEM were $1024 \times 1024$. The actual scales per pixel were commonly set to $0.423 \mu \mathrm{m} \times 0.423 \mu \mathrm{m}$.

Tribological tests were conducted in a sphere-on-flat configuration under starved lubricated conditions. Before each test, $0.5 \mathrm{~mL}$ of L-AN-46 oil was supplied to the inlet side of the contact zone. This lubricant, used in earlier research [31,32], has the following properties: kinematic viscosity at $40{ }^{\circ} \mathrm{C}: 46.0 \mathrm{~mm}^{2} / \mathrm{s}$, kinematic viscosity at $100^{\circ} \mathrm{C}: 6.66 \mathrm{~mm}^{2} / \mathrm{s}$, viscosity index: 96 , ignition temperature: minimum $170{ }^{\circ} \mathrm{C}$, flow temperature: maximum $-12{ }^{\circ} \mathrm{C}$ and density at $15^{\circ} \mathrm{C}: 880 \mathrm{~kg} / \mathrm{m}^{3}$.

Steel discs co-acted with the ball made from $100 \mathrm{Cr} 6$ steel of $60 \mathrm{HRC}$ hardness. The friction radius was $5 \mathrm{~mm}$. The friction force was measured during tests. Tests were carried out at ambient temperature. The number of test repetitions was 3 . Table 2 presents tribological parameters. 
Table 2. Tribological parameters.

\begin{tabular}{ccc}
\hline Normal Force, $\mathbf{N}$ & Sliding Speed, $\mathbf{m} / \mathbf{s}$ & Test Duration, min \\
\hline $10,20,30$ & 0.36 & 10 \\
\hline
\end{tabular}

Dimensions of samples were determined by construction of a tribological tester (the diameter was $25.4 \mathrm{~mm}$, the height was $9 \mathrm{~mm}$ ). Figure 1 presents the scheme of experiments.

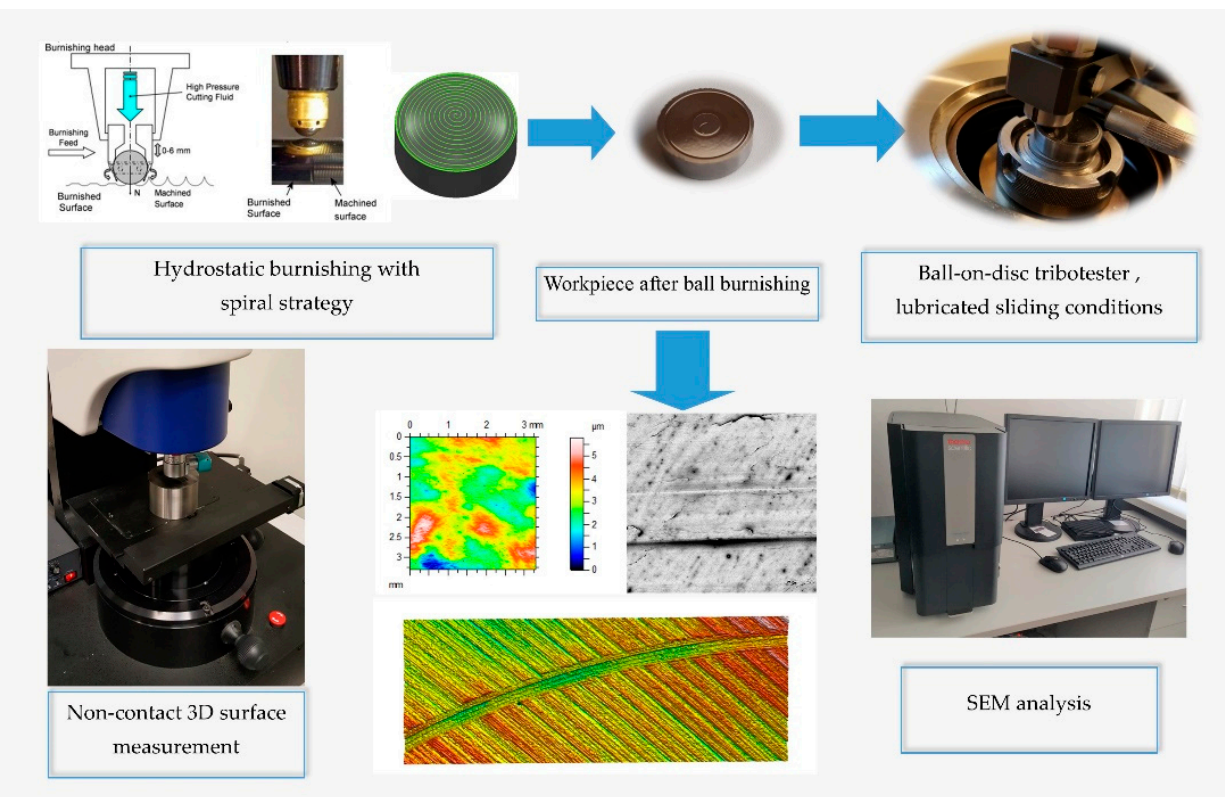

Figure 1. Scheme of experiments.

\section{Surface Texture Analysis of Disc Samples before Tribological Tests}

Table 3 presents the results of surface texture analysis after the treatments. The following parameters from ISO 25178 (Geometric Product Specifications (GPS) —Surface texture: areal) standard were selected: root mean square height (Sq), skewness (Ssk), kurtosis (Sku), maximum peak height (Sp), maximum valley depth (Sv), auto-correlation length (Sal), texture-aspect ratio (Str), root mean square slope (Sdq), density of peaks (Spd) and arithmetic mean peak curvature (Spc). Book [25] presents definitions of these parameters. Figure 2 shows contour plots, Figure 3 presents material ratio curves and ordinate distributions, while Figure 4 shows directionality plots of the analyzed disc samples. Representative profiles of disc samples are presented in Figure 5.

Table 3. Parameters of disc textures.

\begin{tabular}{|c|c|c|c|c|c|c|}
\hline \multirow{2}{*}{$\begin{array}{c}\text { Disc } \\
\text { Pressure }\end{array}$} & \multicolumn{4}{|c|}{ Burnished } & \multirow{3}{*}{ Milled } & \multirow{3}{*}{ Unit } \\
\hline & $10 \mathrm{MPa}$ & $20 \mathrm{MPa}$ & $30 \mathrm{MPa}$ & $40 \mathrm{MPa}$ & & \\
\hline Parameters & - & - & - & - & & \\
\hline $\mathrm{Sq}$ & 0.25 & 0.16 & 0.57 & 0.81 & 0.87 & $\mu \mathrm{m}$ \\
\hline Ssk & -0.23 & -0.21 & 0.12 & 0.12 & 0.41 & - \\
\hline Sku & 3.01 & 4.28 & 2.92 & 3.2 & 2.28 & - \\
\hline $\mathrm{Sp}$ & 0.79 & 1.02 & 2.11 & 2.75 & 2.66 & $\mu \mathrm{m}$ \\
\hline Sv & 1.11 & 0.83 & 1.97 & 3.06 & 2.03 & $\mu \mathrm{m}$ \\
\hline Sal & 0.19 & 0.09 & 0.29 & 0.38 & 0.05 & $\mathrm{~mm}$ \\
\hline Str & 0.4 & 0.56 & 0.84 & 0.56 & 0.03 & - \\
\hline Sdq & 0.024 & 0.014 & 0.059 & 0.052 & 0.072 & - \\
\hline Spd & 392 & 122 & 770 & 280 & 462 & $1 / \mathrm{mm}^{2}$ \\
\hline Spc & 14.03 & 5.89 & 51.4 & 49.4 & 53.9 & $1 / \mathrm{mm}$ \\
\hline
\end{tabular}




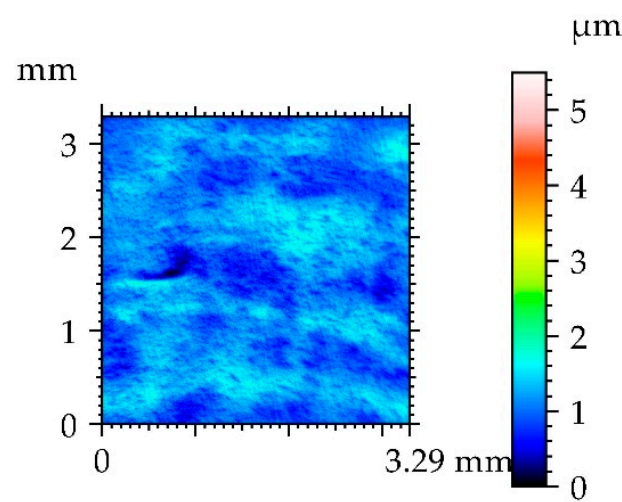

(a)

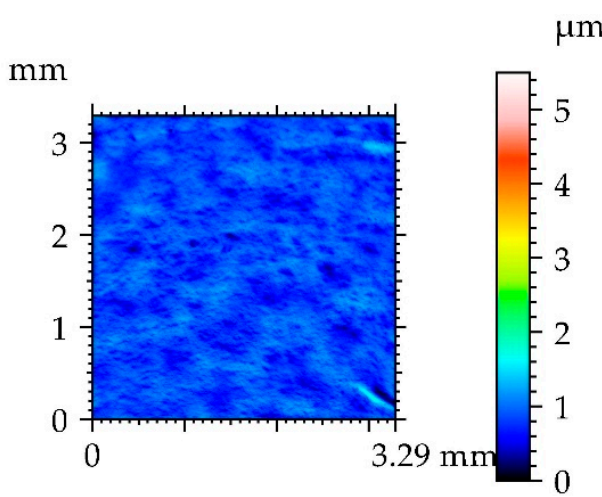

(b)

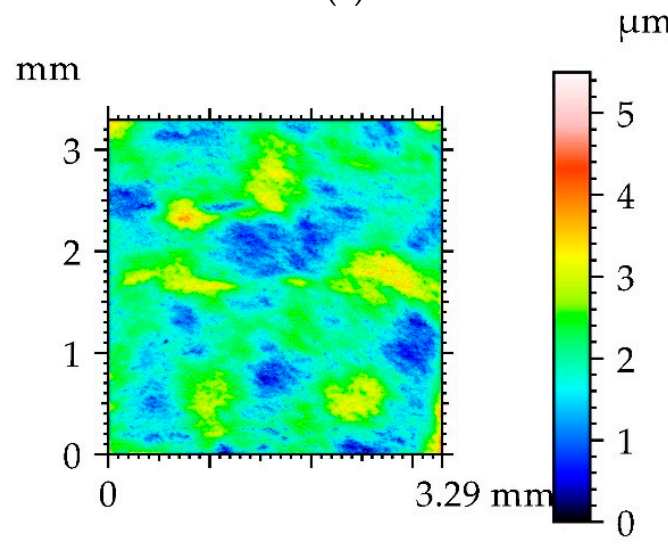

(c)

$u \mathrm{~m}$

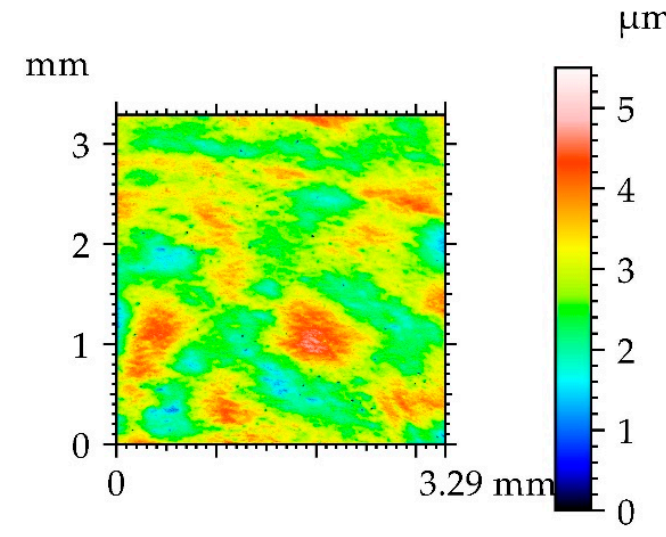

(d)

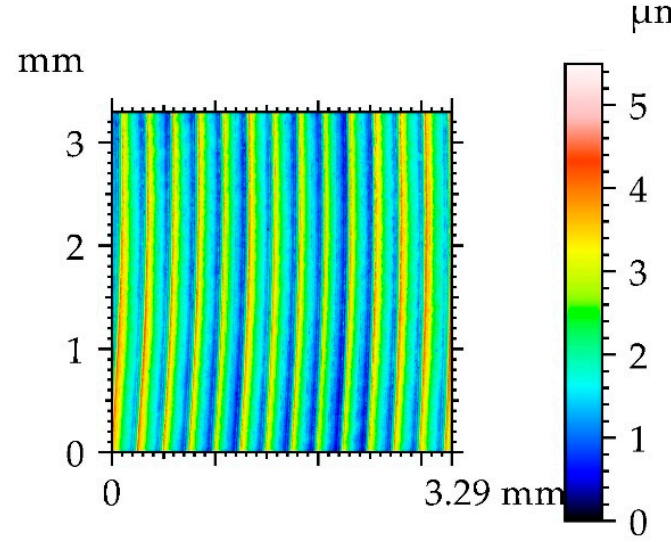

(e)

Figure 2. Contour plots of disc surfaces after burnishing with a pressure (P) of $10 \mathrm{MPa}(\mathbf{a}), 20 \mathrm{MPa}(\mathbf{b})$, $30 \mathrm{MPa}(\mathbf{c}), 40 \mathrm{MPa}(\mathbf{d})$ and after milling (e). 


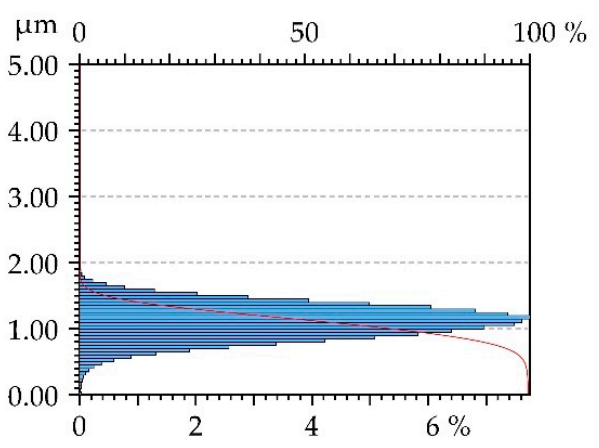

(a)

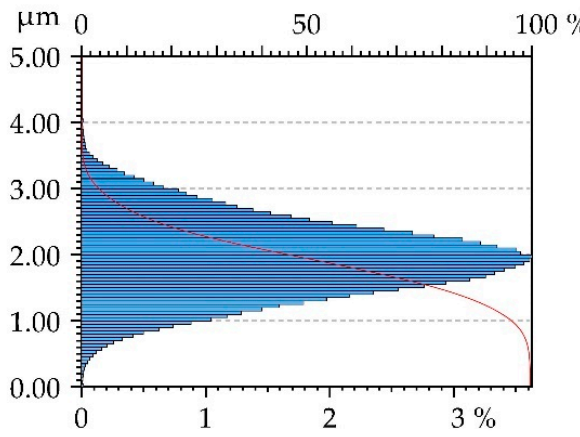

(c)

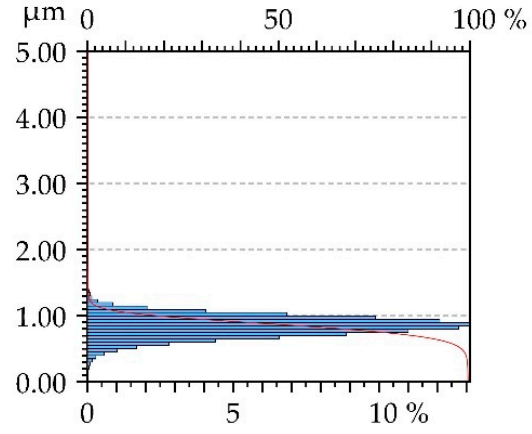

(b)

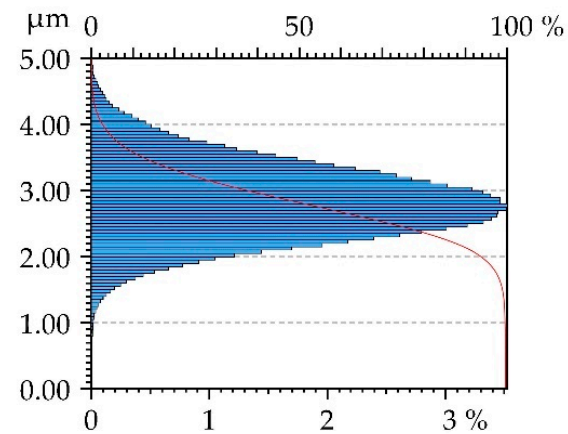

(d)

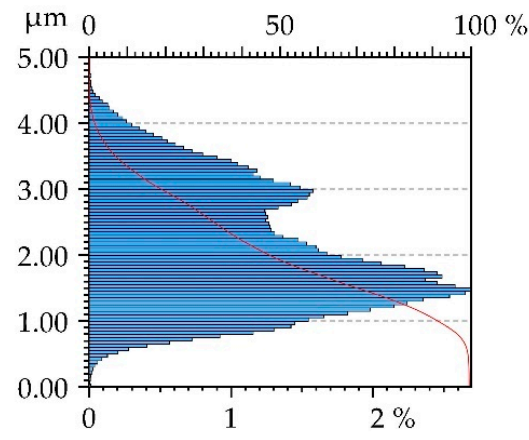

(e)

Figure 3. Material ratio curves and ordinate distributions of disc surfaces after burnishing with a pressure (P) of $10 \mathrm{MPa}(\mathbf{a}), 20 \mathrm{MPa}(\mathbf{b}), 30 \mathrm{MPa}(\mathbf{c}), 40 \mathrm{MPa}(\mathbf{d})$ and after milling (e).

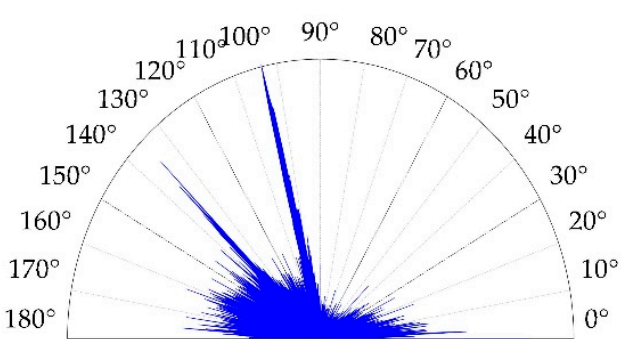

\begin{tabular}{|l|c|l|}
\hline Parameters & Value & Unit \\
\hline Isotropy & 39.88 & $\%$ \\
\hline
\end{tabular}

(a)

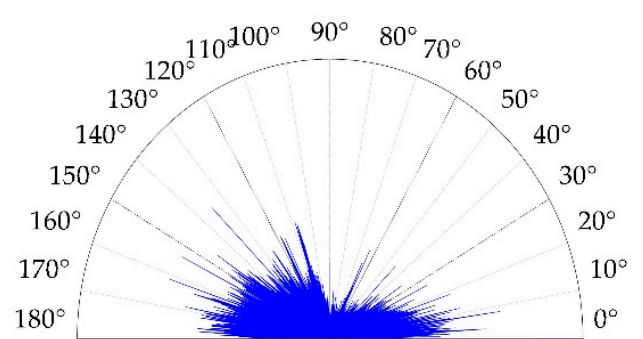

\begin{tabular}{|l|r|l|}
\hline Parameters & Value & Unit \\
\hline Isotropy & 56.11 & $\%$ \\
\hline
\end{tabular}

(b)

Figure 4. Cont. 


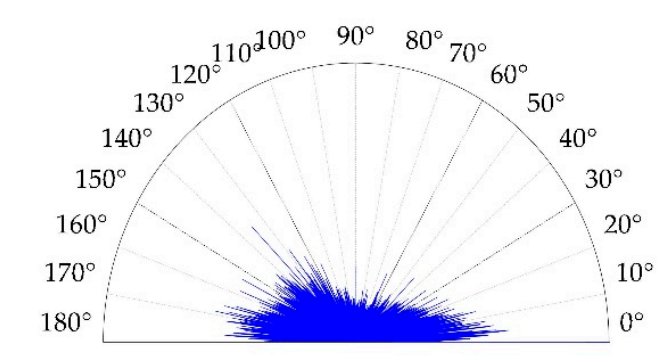

\begin{tabular}{|l|c|l|}
\hline Parameters & Value & Unit \\
\hline Isotropy & 83.65 & $\%$ \\
\hline
\end{tabular}

(c)

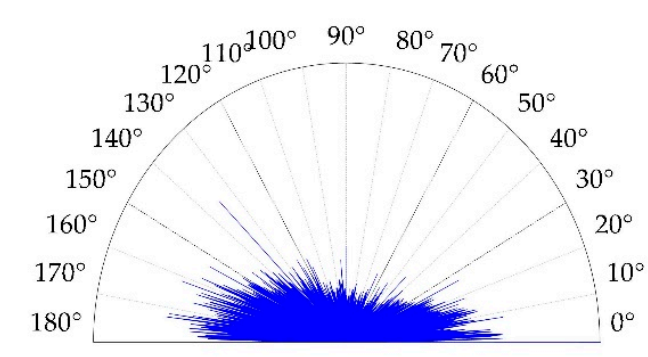

\begin{tabular}{|l|c|l|l|}
\hline Parameters & Value & Unit \\
\hline Isotropy & 70.24 & $\%$ \\
\hline
\end{tabular}

(d)

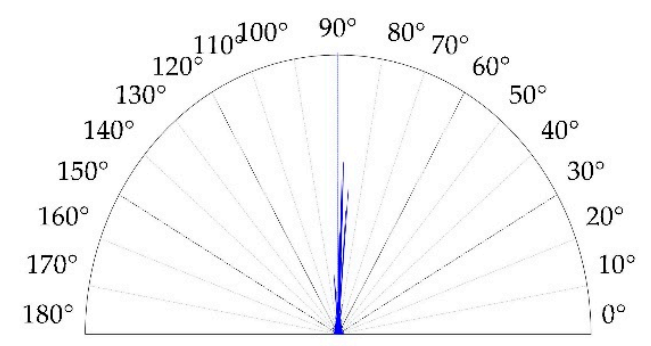

\begin{tabular}{|c|c|c|}
\hline Parameters & Value & Unit \\
\hline Isotropy & 2.74 & $\%$ \\
\hline
\end{tabular}

(e)

Figure 4. Directionality plots of disc surfaces after burnishing with a pressure (P) of $10 \mathrm{MPa}(\mathbf{a}), 20 \mathrm{MPa}$ (b), $30 \mathrm{MPa}(\mathbf{c}), 40 \mathrm{MPa}(\mathbf{d})$ and after milling (e).

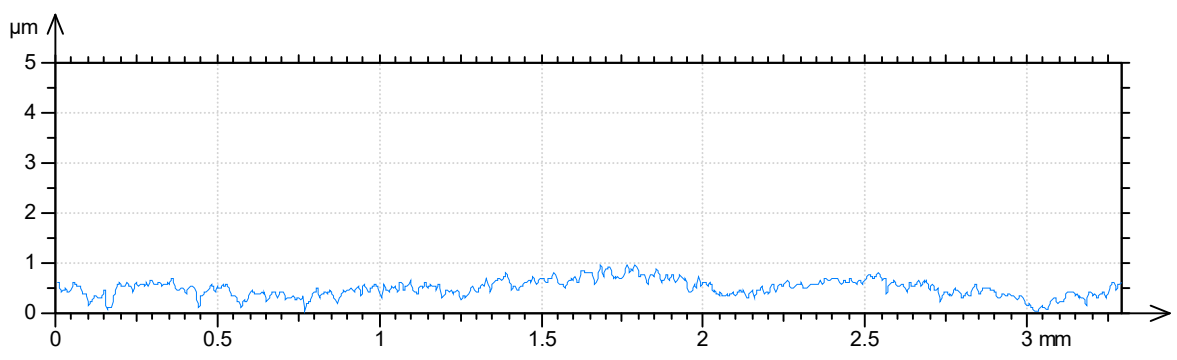

(a)

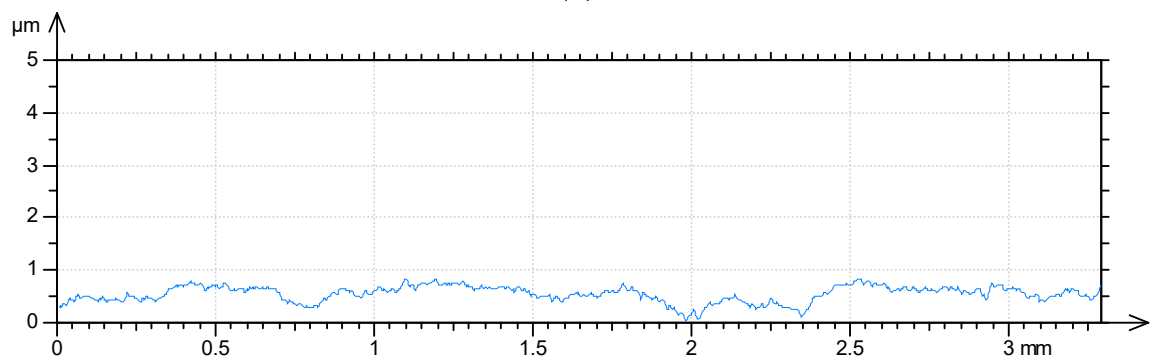

(b)

Figure 5. Cont. 


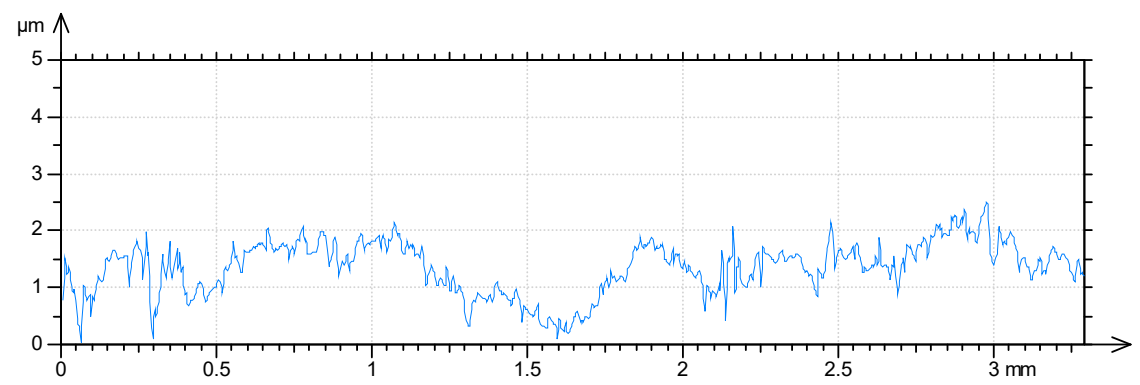

(c)

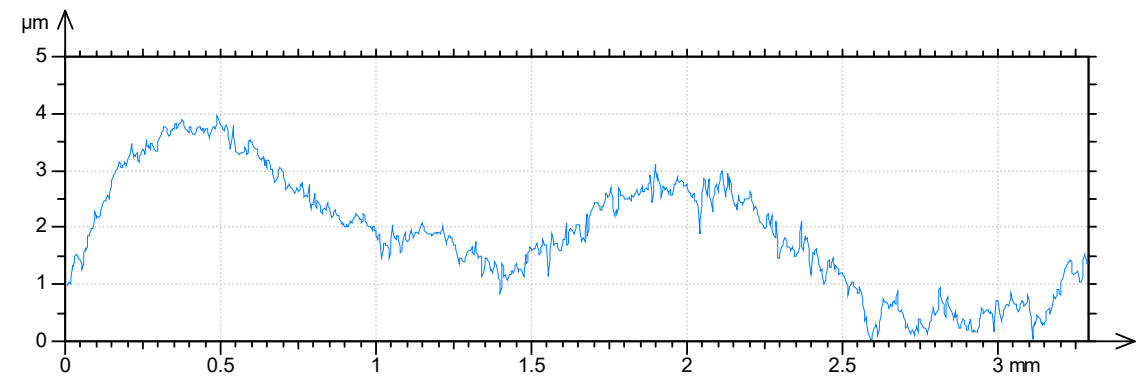

(d)

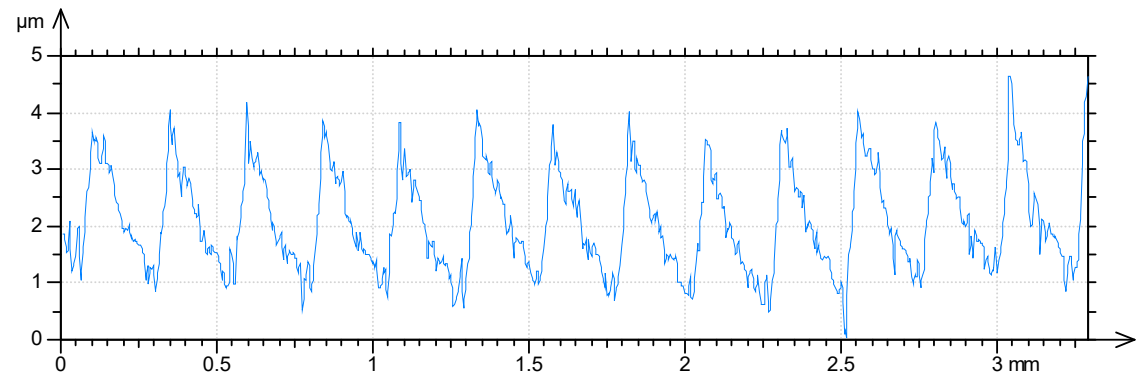

(e)

Figure 5. Representative profiles of burnished disc surfaces when pressure (P) was $10 \mathrm{MPa}(\mathbf{a}), 20 \mathrm{MPa}(\mathbf{b})$, $30 \mathrm{MPa}(\mathbf{c}), 40 \mathrm{MPa}(\mathbf{d})$ and of a milled disc surface (e).

One can see from the analysis of Table 3 and Figures 2, 3 and 5 that the surface after milling is the roughest, followed by surfaces after burnishing. A reduction in surface height was obtained as a result of the burnishing treatment. Burnishing also led to increases in the spatial parameters Sal and Str and to decreases in parameters Sdq and Spc. The smallest height characterized by the Sq, Sp and Sv parameters was achieved for the pressure $(\mathrm{P})$ of $20 \mathrm{MPa}$, followed by the lowest burnishing pressure and higher pressures of 30 and $40 \mathrm{MPa}$. When the material is above the mean plane, the surface is negatively skewed, and in the opposite case, the surface is positively skewed [33,34]. The values of skewness (Ssk) of burnished textures were similar to 0 ; for lower burnishing pressures of 10 and $20 \mathrm{MPa}$, they were a little negative, while for higher pressures of 30 and $40 \mathrm{MPa}$, they were marginally positive. However, the ordinate distributions of burnished surfaces were symmetrical. The kurtosis $(\mathrm{Sku})$ defines how heavily the tails of texture height distribution differ from the tails of a normal distribution. The surface with a high kurtosis tends to have outliers or heavy tails. For the pressures $(\mathrm{P})$ of 10, 30 and $40 \mathrm{MPa}$, kurtosis was similar to 3, for the remaining pressure of $20 \mathrm{MPa}$, the Sku parameter was higher; one can see that the ordinate distribution shown in Figure $3 \mathrm{~b}$ is different from those obtained for other burnishing pressures. There is substantial difference between ordinate distributions of burnished surfaces and the probability distribution of the milled surface (Figure 3e). The values of skewness (0.4) and kurtosis (2.28) of the milled surface are typical for textures after cutting. In addition, the probability distribution of the milled surface is two-modal $[35,36]$. From the analysis of values 
of skewness and kurtosis and from the analysis of probability distributions of the analyzed textures (Figure 3), one can conclude that surfaces after burnishing are random, of the ordinate distributions similar to Gaussian, while the milled surface is deterministic.

The auto-correlation length (Sal) is the lowest for the surface after milling. From among burnished surfaces, the values of the Sal parameter were higher for rougher surfaces. This behavior is characteristic for random surfaces created by the same treatment. The texture-aspect ratio (Str) depends on surface isotropy. The values of the Str parameter of anisotropic surfaces were near 0 , while the values of isotropic surfaces were near 1 . The surface after milling was anisotropic (Figure 4e). The values of the Str parameter of burnished textures were between 40 and $83 \%$. When the burnishing pressure was $20 \mathrm{MPa}$, the isotropic surface was machined, while for the other pressures, mixed surfaces were created. Rms. slope (Sdq) and arithmetical mean peak curvature were typically rougher for bigger surface heights.

An increase in surface topography height for burnishing pressures higher than $20 \mathrm{MPa}$ was probably caused by significant plastic deformation of the disc surfaces.

\section{Results of Tribological Tests and Discussion}

Average values of the coefficient of friction are presented in Figure 6. In order to exclude initial fluctuations, they were computed after five minutes of tests. Figure 7 presents examples of the coefficient of friction runs under different normal loads for various sliding assemblies.

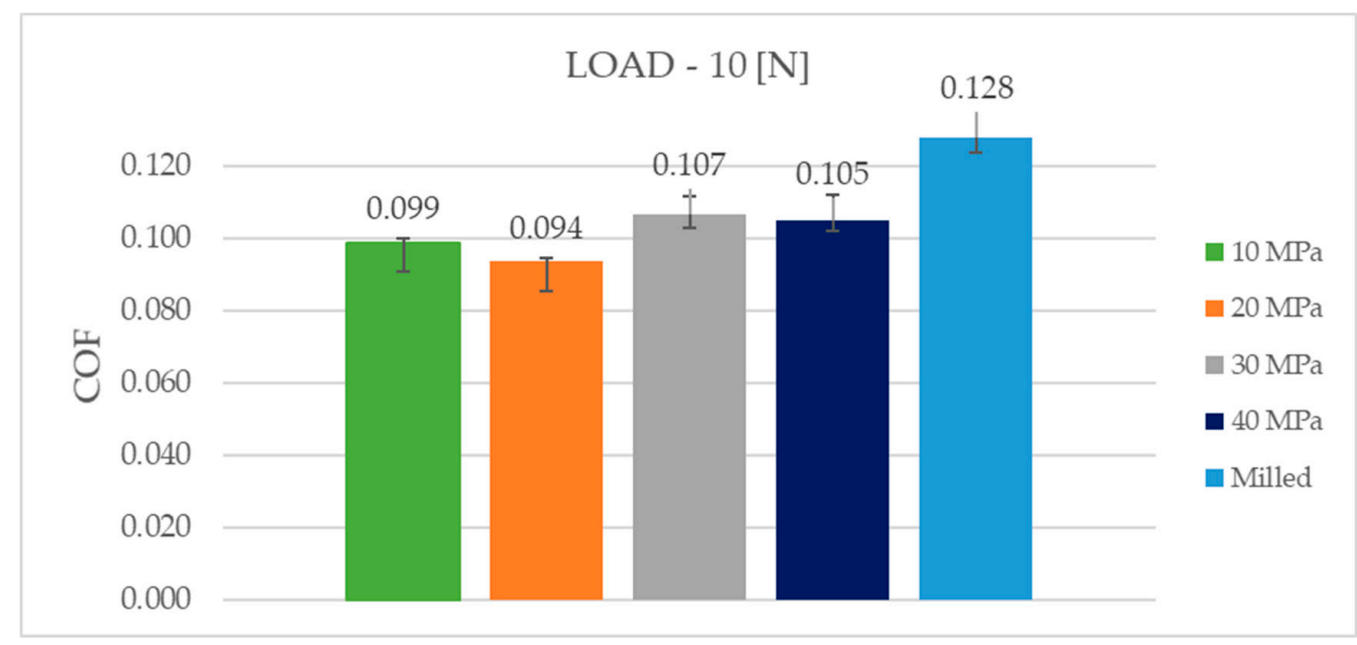

(a)

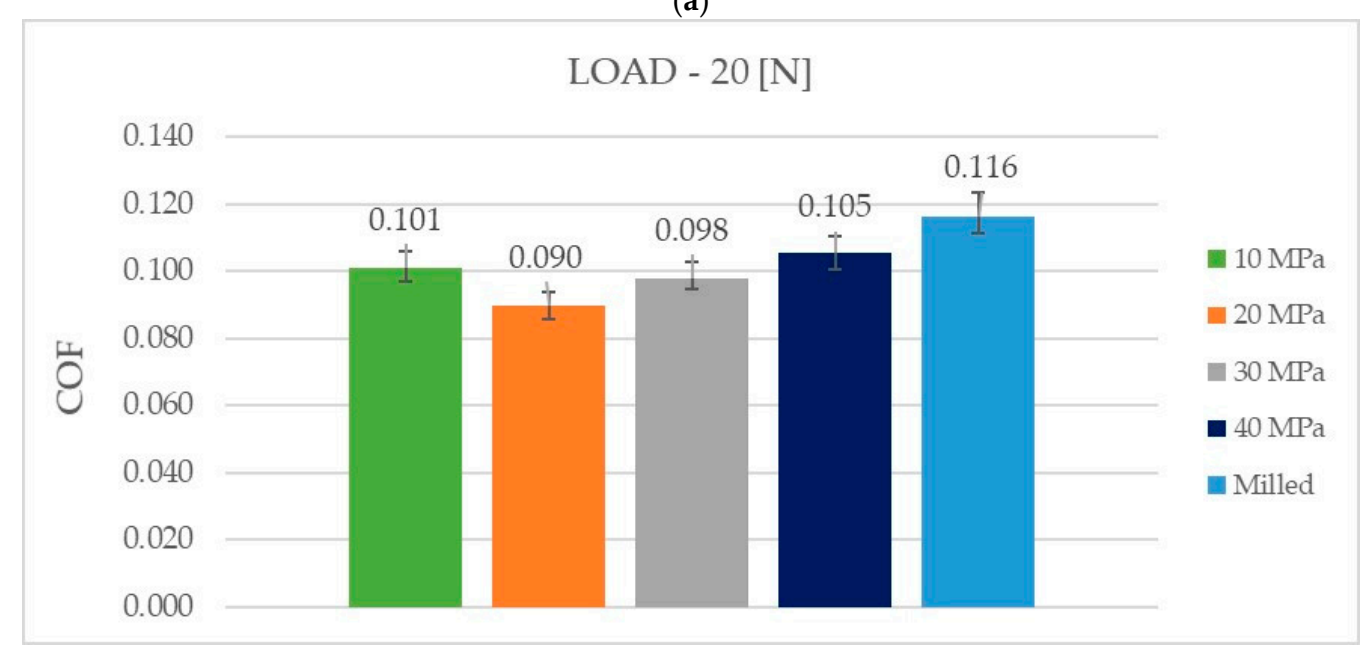

(b)

Figure 6. Cont. 


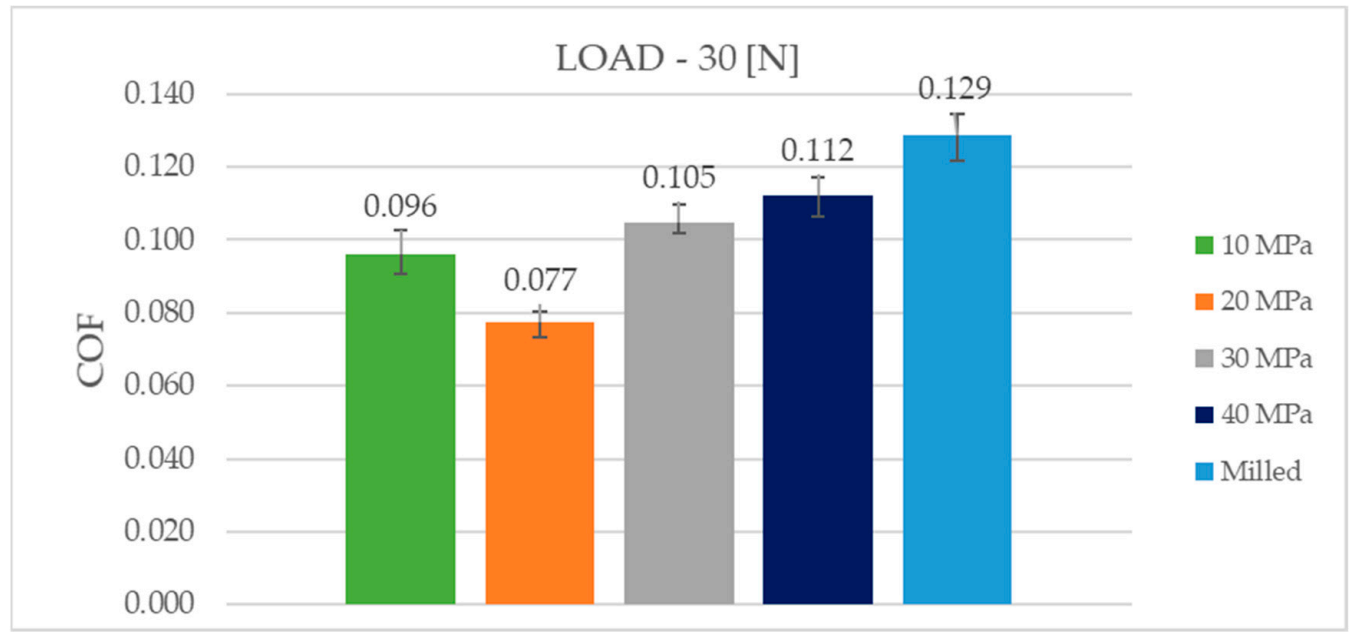

(c)

Figure 6. Average values of the friction coefficient for various assemblies under the load of $10 \mathrm{MPa}(\mathbf{a})$, $20 \mathrm{MPa}(\mathbf{b})$ and $30 \mathrm{MPa}(\mathbf{c})$.

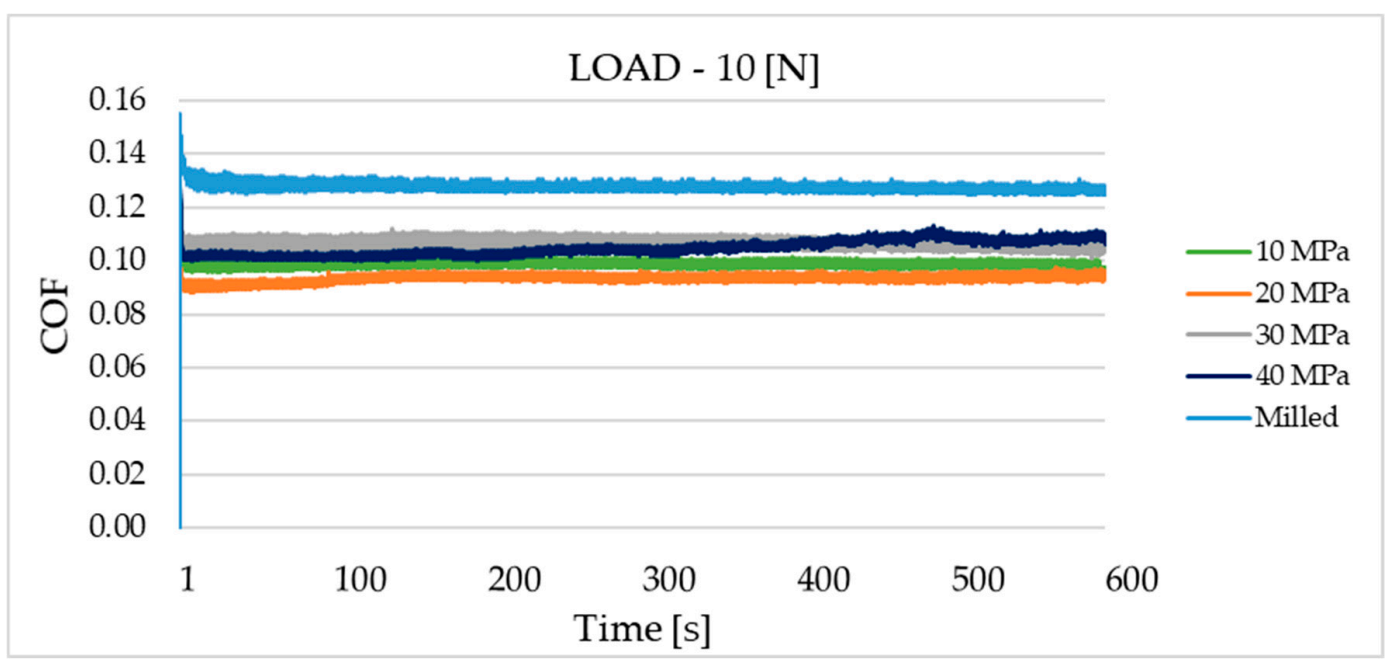

(a)

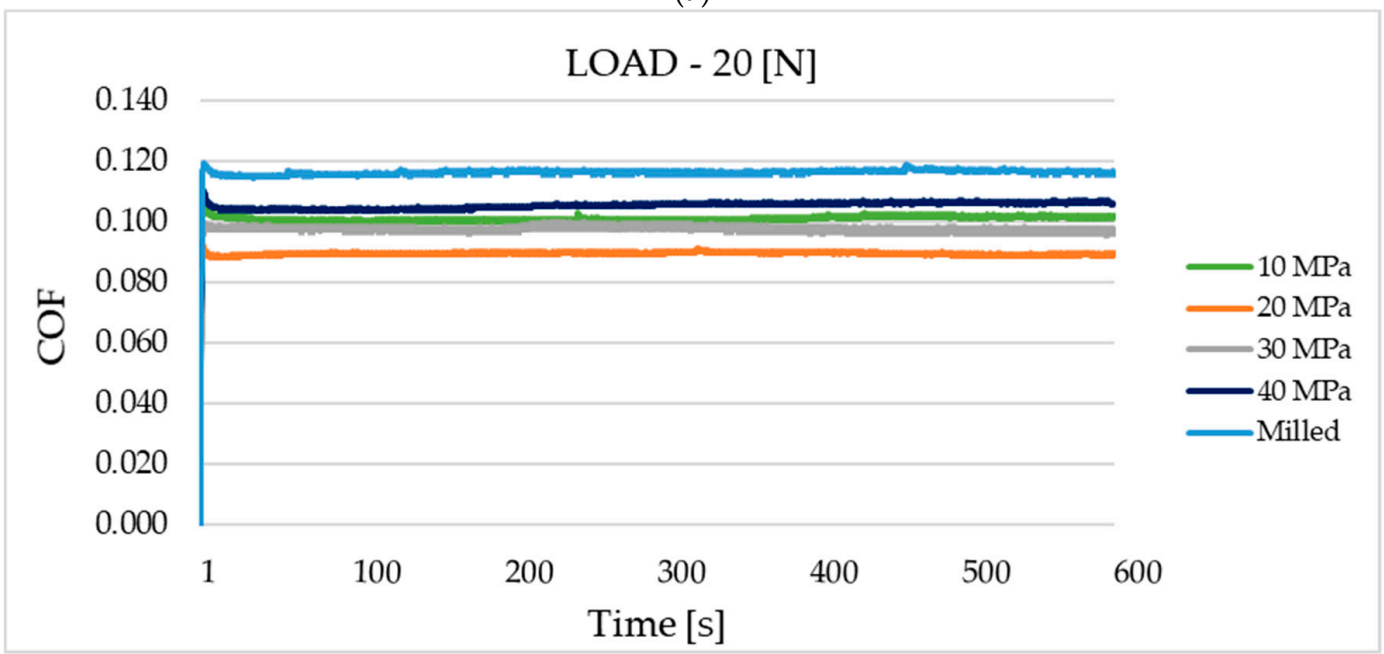

(b)

Figure 7. Cont. 


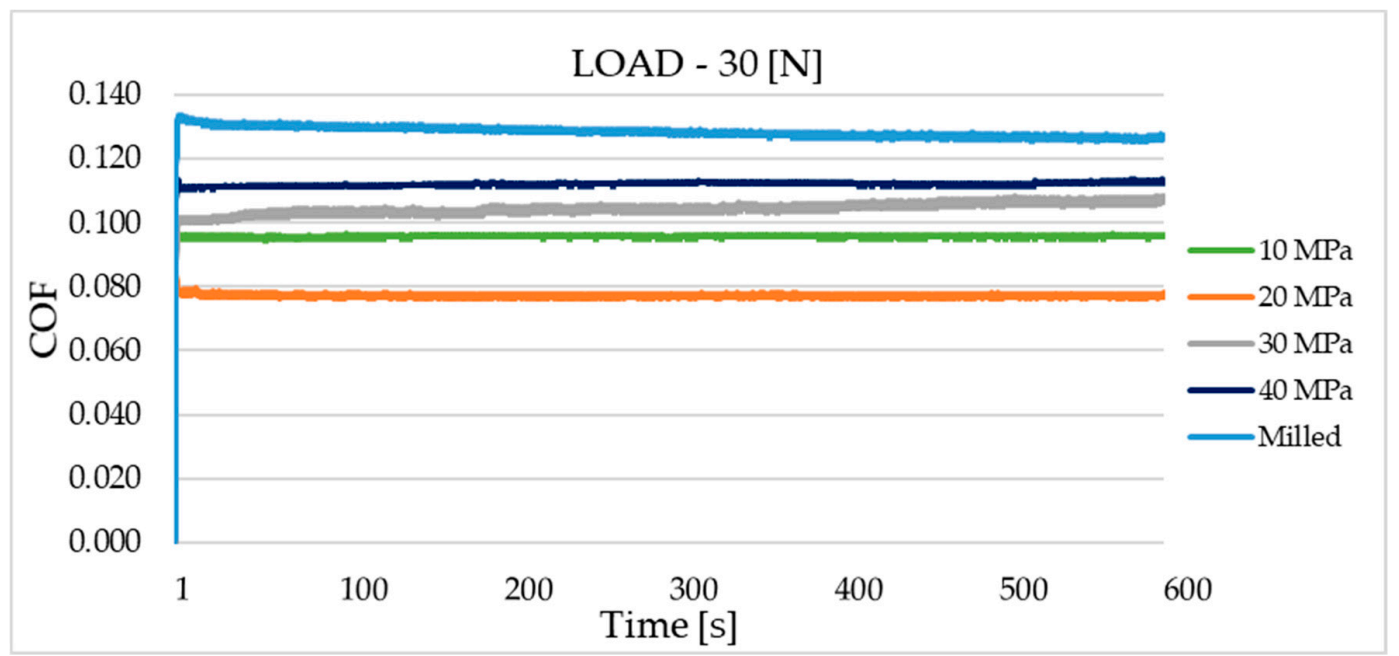

(c)

Figure 7. The friction coefficient against time for various sliding pairs under the load of $10 \mathrm{~N}(\mathbf{a})$, $20 \mathrm{~N}(\mathbf{b})$ and $30 \mathrm{~N}(\mathbf{c})$.

Independently of the normal load applied, the burnishing treatment caused a decrease in the coefficient of friction in comparison to the sliding pair with the sample after milling. The largest decrease was achieved for assembly with the sample burnished under a pressure of $20 \mathrm{MPa}$. The values of the coefficient of friction were typical for mixed lubrication.

For the load of $10 \mathrm{~N}-$ Figure $6 \mathrm{a}$, the highest reduction in friction, in comparison to assembly, which contained the disc after milling, was $26.6 \%$. The application of the smallest burnishing pressure (10 MPa) led to smaller reduction in frictional resistance (of 22.6\%). High burnishing pressures of 30 and $40 \mathrm{MPa}$ led to comparatively high mean coefficients of friction $(0.105-0.107)$, in these cases reductions of the resistance to motion were near $21 \%$. The courses of the coefficient of friction versus time (Figure 7a) were different for sliding pairs with milled samples and for assemblies with burnished specimens. In the first case, after initial fluctuation, the friction force decreased to a small degree. When assemblies with burnished samples were tested, the coefficients of friction increased, as tests progressed. The final value of the coefficient of friction was the highest for the sliding pair with burnished discs with the highest pressure of $40 \mathrm{MPa}$.

When the medium normal load of $20 \mathrm{~N}$ was applied, the highest reduction in the coefficient of friction was $22.4 \%$, due to the application of burnishing-Figure $6 \mathrm{~b}$. When pressures $(\mathrm{P})$ were 10,20 and $40 \mathrm{MPa}$, these reductions were similar to each other; they were a little higher than $10 \%$. The worst results were received when the pressure $(\mathrm{P})$ was the largest. After initial fluctuations, in most cases, the coefficients of friction obtained stable values. Some fluctuations were observed for assemblies with burnished discs with the pressures of 10 and $30 \mathrm{MPa}$ (Figure $7 \mathrm{~b}$ ).

The highest reduction in the mean coefficient of friction due to burnishing was achieved for the highest normal load of $30 \mathrm{~N}$-it was larger than $40 \%$ when the burnished pressure was $20 \mathrm{MPa}$. For assemblies with discs treated with the pressures of 10,30 and $40 \mathrm{MPa}$, the decreases were 25.5, 18.6 and $13.2 \%$, respectively-Figure 6c. Similar to the smallest load, the coefficient of friction of the sliding pair with the milled sample decreased with time. Different courses of the friction coefficient were observed when the burnished discs were tested. For burnishing pressures of 10, 20 and $40 \mathrm{MPa}$, after initial changes, the friction force was stable. However, when the burnished disc with the pressure of $30 \mathrm{MPa}$ was tested, the coefficient of friction increased as the test progressed-Figure $7 \mathrm{c}$.

The increase in the coefficient of friction with time of the burnished samples (Figure 7a,c) was probably caused by a reduction in the volume of oil in the contact zone. The milled sample with the biggest roughness height contained valleys, which retained lubricant. Therefore, in this case, the fiction force was stable or increased as the test progressed. 
The obtained coefficient of friction was independent of the normal load used. The average coefficient of friction was near 0.1. This performance is probably related to low wear of the co-acting parts. Typically, due to better sliding surfaces matching, which resulted from an increase in the normal pressure, the coefficient of friction decreased for the higher normal load. Burnishing treatment led to the highest decrease in the coefficient of friction for the highest normal load of 30 N. Further research should be conducted with higher contact pressures.

As the tested sliding assemblies were lubricated and the test duration was low, it was difficult to measure wear levels of all tested discs. Wear tracks were more visible when normal loads were higher. It was found that when the coefficients of friction were higher, the sizes of the wear tracks were also larger. Figures 8 and 9 present worn surfaces of the milled sample and the sample burnished with the pressure of $20 \mathrm{MPa}$. The milled sample led to the highest and the burnished sample led to the lowest value of the coefficient of friction (Figure 7c). One can see that both depth and width of wear track were higher for the milled sample compared to those of the burnished one-Figure 9. From the analysis of Figure 9, one can see that wear of disc had abrasive character.

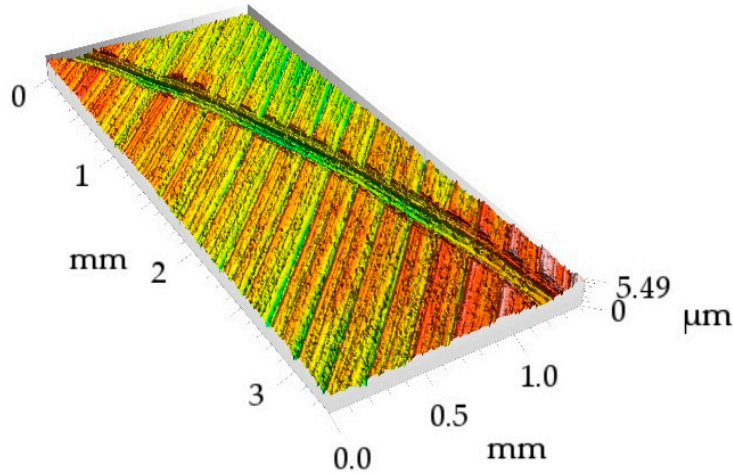

(a)

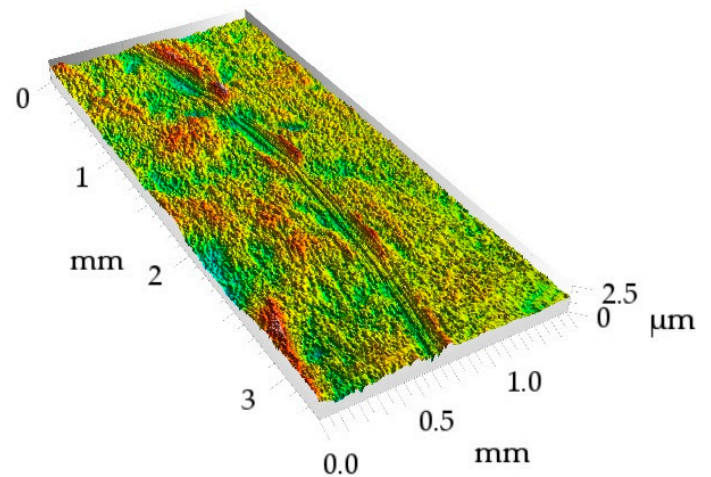

(b)

Figure 8. Isometric view of the milled surface (a) and of the burnished surface with a pressure of $20 \mathrm{MPa}(\mathbf{b})$ after tribological tests at the normal load of $30 \mathrm{~N}$

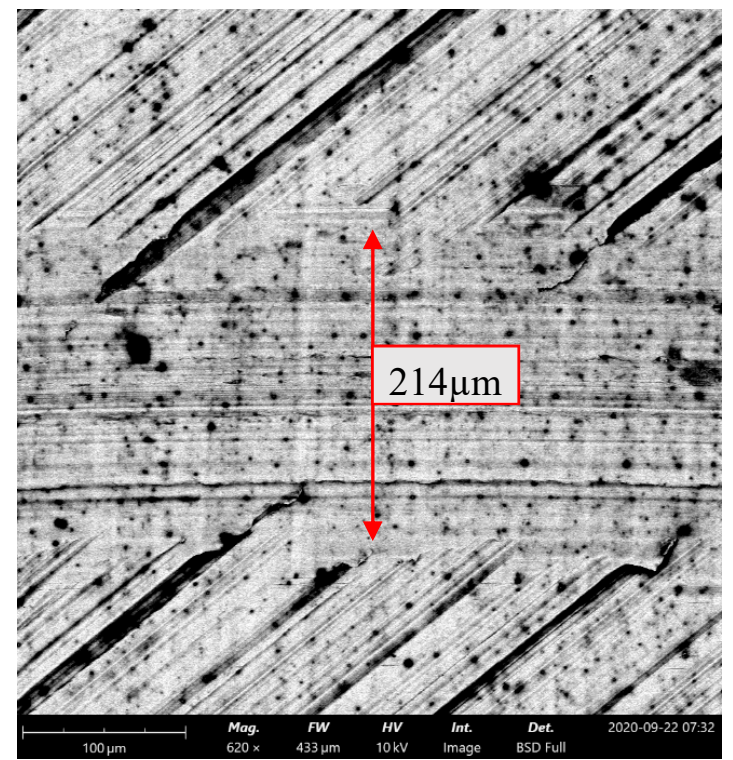

(a)

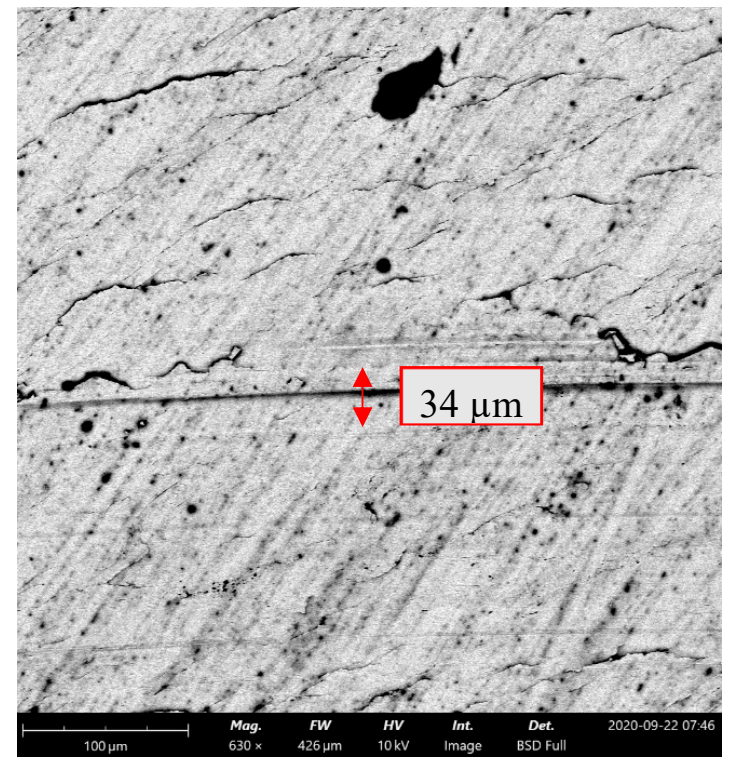

(b)

Figure 9. SEM views of the milled surface (a) and burnished surface with pressure of $20 \mathrm{MPa}(\mathbf{b})$ after tribological tests at the normal load of $30 \mathrm{~N}$. 
The smallest friction coefficient of the assembly with the burnished disc with the pressure of $20 \mathrm{MPa}$ was caused by the smallest height of surface texture. The Sq parameter of this sample was the smallest of all analyzed disc surfaces. It is also important that the surface slope (Sdq) was also the lowest. These parameters were about $40 \%$ smaller than those from the burnished surface with the pressure of $10 \mathrm{MPa}$. The average peak curvature $(\mathrm{Spc})$ of the burnished surface with the pressure of $20 \mathrm{MPa}$ is also much lower than that of the burnished surface with the lowest pressure. This means that the mean summit radius of the curvature of the burnished surface with the pressure of $20 \mathrm{MPa}$ was more than two times larger. A common, contemporary friction model identifies two major sources of friction: the deformation of contacting asperities during relative motion and interfacial adhesion between the contacting asperities. In lubricated tests, the adhesion effect is negligible, while resistance to motion due to the deformation of contacting asperities is higher for the higher surface roughness of the contacting bodies. The very small rms. slope and large radius of asperity curvature of the burnished surface with the pressure of $20 \mathrm{MPa}$ can also contribute to lower resistance to motion. Higher coefficients of friction of rougher samples in lubricated contact were also found in other works [20-23].

For the smallest and the largest normal forces, the coefficients of friction of assembly with the disc treated with the pressure of $10 \mathrm{MPa}$ were smaller than those obtained for burnished discs with the pressures of 30 and $40 \mathrm{MPa}$. This tribological behavior was also probably caused by the smaller texture height, slope and the average asperity curvature of the disc treated with the pressure of $10 \mathrm{MPa}$, compared to those obtained for pressures of 30 and $40 \mathrm{MPa}$. For the medium and the highest normal load, the disc with the burnished surface with the pressure of $30 \mathrm{MPa}$ led to smaller coefficient of friction compared to the disc surface treated with the highest pressure used-40 MPa. This behavior was also caused by the smaller roughness height of the disc burnished with the pressure of $30 \mathrm{MPa}$. The isotropic character of this surface $(S \operatorname{st}=0.84)$ could be also the reason for the smaller resistance to motion of this surface compared to that of the surface treated with the highest pressure, this surface was characterized by smaller value of the Str parameter (0.56).

The ball burnishing process is applied to improve surface quality. An increase in the burnishing pressure from 10 to $20 \mathrm{MPa}$ led to an improvement in surface roughness, and the amplitude parameters decreased. However, further increase in the burnishing pressure led to an increase in the surface topography height of the disc sample. This increase was probably caused by the plastic deformation, which caused the delamination of the surface layer.

Burnishing led to a decrease in the coefficient of friction of analyzed sliding pairs independently to the burnished pressure. The highest resistance to motion of the assembly with the milled sample was caused by the highest roughness height, characterized by the Sq parameter. The highest rms. slope (Sdq) and arithmetical mean peak curvature (Spc) of the milled surface can be also important. The anisotropic character of the milled sample can also cause high resistance to motion of the sliding assembly. A positive skewness of the milled sample can also influence high coefficients of friction, because this kind of surface contains more peaks than valleys. The beneficial effect of ball burnishing on the tribological behavior of sliding elements was also found in the previous investigation of the present authors under dry friction conditions [13].

\section{Conclusions}

In this paper, the effect of ball burnishing of steel disc samples on the coefficient of friction in lubricated sliding was studied. The authors of this paper have not found similar research studies in technical literature.

Ball burnishing of the surface after milling caused decreases in roughness height, slope and arithmetical peak curvature and led to increases in values of spatial parameters-Sal and Str. The smallest disc roughness height was achieved for the burnishing pressure of $20 \mathrm{MPa}$ followed by the disc burnished with the pressures of 10, 30 and $40 \mathrm{MPa}$. 
Ball burnishing in all analyzed cases caused a reduction in the friction coefficient, in comparison to that obtained for assembly with the sample after milling. Higher amplitude of texture corresponded to higher coefficient of friction. The best results were achieved for the sample burnished with the pressure of $20 \mathrm{MPa}$. Ball burnishing led to the highest decrease in the coefficient of friction (near 40\%) for the highest normal load of $30 \mathrm{~N}$.

It was impossible to assess the wear of all tested disc samples quantitatively. Wear tracks were more visible for larger normal loads. The larger coefficient of friction corresponded to higher wear levels of discs. Wear had abrasive characteristics.

Author Contributions: Conceptualization: P.P., S.S.; methodology, investigation, and formal analysis: S.S.; writing - original draft preparation: P.P., S.S.; writing—review and editing: P.P., S.S. All authors have read and agreed to the published version of the manuscript.

Funding: This research received no external funding.

Conflicts of Interest: The authors declare no conflict of interest.

\section{References}

1. Alshareef, A.; Marinescu, I.; Basudan, I.; Alqahtani, B.; Tharwan, M. Ball-burnishing factors affecting residual stress of AISI 8620 steel. Int. J. Adv. Manuf. Technol. 2020, 107, 1387-1397. [CrossRef]

2. Rodriguez, A.; De Lacalle, L.; Celaya, A.; Lamikiz, A.; Albizuri, J.; De Lacalle, L.; Lamikiz, A. Surface improvement of shafts by the deep ball-burnishing technique. Surf. Coat. Technol. 2012, 206, 2817-2824. [CrossRef]

3. De Lacalle, L.; Lamikiz, A.; Munoa, J.; Sanchez, J.; Lamikiz, A. Quality improvement of ball-end milled sculptured surfaces by ball burnishing. Int. J. Mach. Tools Manuf. 2005, 45, 1659-1668. [CrossRef]

4. Charfeddine, Y.; Youssef, S.; Sghaier, S.; Hamdi, H. Finite Element Residual Stress Computation for Combined Grinding/Burnishing Applied to 100Cr6 Steel. In Advances in Mechanical Engineering, Materials and Mechanics; Lecture Notes in Mechanical Engineering; Kharrat, M., Baccar, M., Dammak, F., Eds.; Springer: Cham, Switzerland, 2019. [CrossRef]

5. Grzesik, W.; Zak, K. Modification of surface finish produced by hard turning using superfinishing and burnishing operations. J. Mater. Process. Technol. 2012, 212, 315-322. [CrossRef]

6. Swirad, S.; Wydrzynski, D.; Nieslony, P.; Krolczyk, G. Influence of hydrostatic burnishing strategy on the surface topography of martensitic steel. Measurement 2019, 138, 590-601. [CrossRef]

7. Korzynski, M.; Zarski, T. Slide diamond burnishing influence on of surface stereometric structure of an AZ91 alloy. Surf. Coat. Technol. 2016, 307, 590-595. [CrossRef]

8. Buldum, B.; Cagan, S. Study of ball burnishing process on the surface roughness and microhardness of AZ91D alloy. Exp. Tech. 2018, 42, 233-241. [CrossRef]

9. Cobanoglu, T.; Ozturk, S. Effect of burnishing parameters on the surface quality and hardness. Proc. Inst. Mech. Eng. Part B J. Eng. Manuf. 2015, 229, 286-294. [CrossRef]

10. Saldaña-Robles, A.; Plascencia-Mora, H.; Aguilera-Gómez, E.; Saldaña-Robles, E.; Marquez-Herrera, A.; Diosdado-De la Peña, J. Influence of ball-burnishing on roughness, hardness and corrosion resistance of AISI 1045 steel. Surf. Coat. Technol. 2018, 339, 191-198. [CrossRef]

11. Revankar, G.; Shetty, R.; Rao, S.; Gaitonde, V. Analysis of surface roughness and hardness in ball burnishing of titanium alloy. Measurement 2014, 58, 256-268. [CrossRef]

12. Skoczylas, A.; Zaleski, K. Selected Properties of the Surface Layer of C45 Steel Parts Subjected to Laser Cutting and Ball Burnishing. Materials 2020, 13, 3429. [CrossRef]

13. Swirad, S.; Pawlus, P. The Effect of Ball Burnishing on Tribological Performance of 42CrMo4 Steel under Dry Sliding Conditions. Materials 2020, 13, 2127. [CrossRef]

14. Hamadache, H.; Bourebia, M.; Taamallah, O.; Laouar, L. Surface hardening of 36 NiCrMo 6 steel by ball burnishing process. Mater. Res. Express 2019, 6, 106538. [CrossRef]

15. Swirad, S. Surface texture analysis after hydrostatic burnishing on X38CrMoV5-1 steel. Chin. J. Mech. Eng. 2019, 32, 91. [CrossRef]

16. Dzionk, S.; Scibiorski, B.; Przybylski, W. Surface texture analysis of hardened shafts after ceramic ball burnishing. Materials 2019, 12, 204. [CrossRef] 
17. Revankar, G.; Raviraj, S.; Shrikantha, S.; Vinayak, N. Wear resistance enhancement of titanium alloy (Ti-6Al-4V) by ball burnishing process. J. Mater. Res. Technol. 2017, 6, 13-32. [CrossRef]

18. Travieso-Rodríguez, J.; Jerez-Mesa, R.; Gómez-Gras, G.; Llumà-Fuentes, J.; Casadesús-Farràs, O.; Madueño-Guerrero, M. Hardening effect and fatigue behavior enhancement through ball burnishing on AISI 1038. J. Mater. Res. Technol. 2019, 8, 5639-5646. [CrossRef]

19. Pohrelyuk, I.; Fedirko, V.; Lavrys, S. Effect of preliminary ball burnishing on wear resistance of the nitrided VT22 alloy. J. Frict. Wear 2017, 38, 221-224. [CrossRef]

20. Dzierwa, A.; Pawlus, P.; Zelasko, W.; Reizer, R. The study of the tribological properties of one-process and two-process textures after vapour blasting and lapping using pin-on-disc tests. Key Eng. Mater. 2013, 527, 217-222. [CrossRef]

21. Sedlacek, M.; Podgornik, B.; Vizintin, J. Correlation between standard roughness parameters skewness and kurtosis and tribological behaviour of contact surfaces. Tribol. Int. 2012, 48, 102-112. [CrossRef]

22. Sedlacek, M.; Podgornik, B.; Vizintin, J. Influence of surface preparation on roughness parameters, friction and wear. Wear 2009, 266, 482-487. [CrossRef]

23. Lu, R.; Zhang, H.; Mitsuya, Y.; Fukuzawa, K.; Itoh, S. Influence of surface roughness and coating on the friction properties of nanometer-thick liquid lubricant films. Wear 2014, 193, 56-61. [CrossRef]

24. Yamaguchi, K.; Sasaki, C.; Tsuboi, R.; Atherton, M.; Stolarski, T.; Sasaki, S. Effect of surface roughness on friction behaviour of steel under boundary lubrication. Proc. Inst. Mech. Eng. J. 2014, 228, 1015-1019. [CrossRef]

25. Leach, R. Characterisation of Areal Surface Texture; Leach, R., Ed.; Springer: Berlin, Germany, 2013.

26. Jeng, Y. Impact of plateaued surfaces on Tribological performance. Tribol. Trans. 1996, 39, 354-361. [CrossRef]

27. Srivastava, D.; Agarwal, A.; Kumar, J. Effect of liner surface properties on wear and friction in a non-firing engine simulator. Mater. Des. 2007, 28, 1632-1640. [CrossRef]

28. Johansson, S.; Nilsson, P.; Ohlsson, R.; Anderberg, C.; Rosen, B. New cylinder liner surfaces for low oil consumption. Tribol. Int. 2008, 41, 854-859. [CrossRef]

29. Hill, S. Cylinder Bore Finishes and Their Effect on Oil Consumption. Available online: https://www.sae.org/ publications/technical-papers/content/2001-01-3550/ (accessed on 8 October 2020).

30. Etsion, I. State of the art in laser surface texturing. J. Tribol. 2005, 125, 248-253. [CrossRef]

31. Wos, S.; Koszela, W.; Pawlus, P. Determination of oil demand for textured surfaces under conformal contact conditions. Tribol. Int. 2016, 93, 602-613. [CrossRef]

32. Wos, S.; Koszela, W.; Pawlus, P. The effect of both surfaces textured on improvement of tribological properties of sliding elements. Tribol. Int. 2017, 113, 137-148. [CrossRef]

33. Gadelmawla, E.; Koura, M.; Maksoud, T.; Elewa, I.; Soliman, H. Roughness parameters. J. Mater. Process. Technol. 2002, 123, 133-145. [CrossRef]

34. Pawlus, P.; Reizer, R.; Wieczorowski, M. Characterization of the shape of ordinate distribution of two-process profile. Measurement 2020, 153, 107387. [CrossRef]

35. Pawlus, P.; Reizer, R.; Wieczorowski, M.; Krolczyk, G. Material ratio curve as information on the state of surface topography-A review. Precis. Eng. 2020, 65, 240-258. [CrossRef]

36. Pawlus, P.; Reizer, R.; Wieczorowski, M. Conditions of the Presence of Bimodal Amplitude Distribution of Two-Process Surfaces. Materials 2020, 13, 4037. [CrossRef]

Publisher's Note: MDPI stays neutral with regard to jurisdictional claims in published maps and institutional affiliations.

(C) 2020 by the authors. Licensee MDPI, Basel, Switzerland. This article is an open access article distributed under the terms and conditions of the Creative Commons Attribution (CC BY) license (http://creativecommons.org/licenses/by/4.0/). 